\title{
Distinct Sites of Production and Deposition of the Putative Cell Death Marker Clusterin in the Human Thymus
}

\author{
Lars E. French, André-Pascal Sappino, * Jürg Tschopp, ${ }^{\star}$ and Jürg A. Schifferli \\ Divisions of Nephrology and *Oncology, Hôpital Cantonal Universitaire, 1211 Geneva 4, Switzerland; and \\ ${ }^{\ddagger}$ Institute of Biochemistry, University of Lausanne, 1066 Epalinges, Switzerland
}

\begin{abstract}
Clusterin is a multifunctional protein endowed with cell-aggregating, complement-inhibitory, and lipid-binding properties. Since several studies have demonstrated highly increased clusterin gene expression in epithelial and nervous tissues regressing as a consequence of tissue involution and apoptotic cell death, clusterin is also considered as a specific marker of dying cells. To determine whether clusterin expression is also upregulated during thymocyte death occurring during the negative selection process we analyzed the cellular distribution of clusterin mRNA and protein by in situ hybridization and immunocytochemistry in the human thymus. We observed that the expression of clusterin mRNA was confined to cells present in the thymic medulla, concentrated mainly around Hassal's bodies. Immunostaining of adjacent sections with antikeratin $\mathbf{A b}$ revealed that cells containing clusterin mRNA were predominantly epithelial. By contrast no clusterin mRNA was found in thymocytes by in situ hybridization and Northern blot analysis of total RNA from purified thymocyte populations. Clusterin protein colocalized with the membrane attack complex of complement and vitronectin in the center of the largest Hassal's bodies, but was not detectable by immunocytochemistry in or at the surface of epithelial cells. Our results demonstrate that clusterin gene expression does not take place in apoptotic thymocytes, and therefore that clusterin synthesis by the dying cell is probably not a prerequisite to its death. However, synthesis of clusterin by medullary epithelial cells may be related to their terminal differentiation, and, furthermore, its presence in Hassal's bodies raises the possibility that the secreted protein is involved in the disposal of cell debris resulting from thymocyte apoptosis. (J. Clin. Invest. 1992. 90:1919-1925.) Key words: apoptosis • in situ hybridization • complement • Hassal's bodies - lipid redistribution
\end{abstract}

\section{Introduction}

Clusterin is a secretory glycoprotein present in human serum at concentrations ranging from $50-100 \mu \mathrm{g} / \mathrm{ml}$, and at approximately 10 times higher concentrations in human seminal plasma (1-4). Many tissues express clusterin mRNA, the high-

Address correspondence to Dr. L. E. French, Laboratoire d'ImmunoNéphrologie, Centre Medical Universitaire, 1 rue Michel-Servet, 1211 Geneva 4, Switzerland.

Received for publication 21 February 1992 and in revised form 29 May 1992.

J. Clin. Invest.

(C) The American Society for Clinical Investigation, Inc.

$0021-9738 / 92 / 11 / 1919 / 07 \quad \$ 2.00$

Volume 90, November 1992, 1919-1925 est levels being detected in the testes, the brain, the adrenal medulla, the liver, the pituitary gland, and the ovary (5-7).

Several functions have been attributed to clusterin since its initial characterization by Fritz and colleagues in 1983 as the major glycoprotein of ram rete testis fluid (8). Its first discovered property was the ability to aggregate Sertoli cells in vitro, and this has since been extended to various other homologous and heterologous cell types $(9,10)$. More recently, clusterin has been isolated from the soluble, cytolytically inactive form of the membrane attack complex of complement (MAC) $)^{1}(1$, $2,4)$. It has been shown to bind to the nascent $\mathrm{C} 5 \mathrm{~b}-\mathrm{C} 6$ complex in a similar manner to vitronectin thereby suppressing the cytolytic potential of the MAC and rendering it soluble (11-13). Several observations including its colocalization with MAC in kidney diseases, experimental Heymann nephritis and lupus skin disease suggest that clusterin regulates the terminal complement cascade in vivo as well $(1,14-16)$. In addition, clusterin is now known to complex with apolipoprotein A-1 forming a minor subclass of high density lipoproteins, indicating that it also participates in lipid transport and local lipid redistribution (17-19).

There is growing evidence that clusterin may be involved in tissue remodeling. The expression of the clusterin gene is highly increased during the involution of certain tissues in response to developmental stimuli, hormonal modulations, or injury. Indeed, clusterin (or species homologous) transcripts and/or protein have been localized for example in: regressing interdigital tissue of fetal rat limb buds (20), prostatic epithelial cells after castration (20-23), renal collecting ducts and distal tubules after ureteral obstruction $(20,24)$, and rat hippocampus after experimental deafferentiation (25). Furthermore, there is substantial evidence that cell death occurring during the involution of these tissues is apoptotic.

Apoptosis is an active cell death process that takes place in a spectrum of physiological conditions such as embryonic development, metamorphosis, "normal cell turnover," and hormone-dependent atrophy. It differs both morphologically and biochemically from necrotic cell death in that it is characterized by: $(a)$ a reduction of cell volume; $(b)$ chromatin condensation; $(c)$ fragmentation of DNA into multiples of nucleosome-sized pieces; and $(d)$ the requirement for RNA and protein synthesis (26-30). In the thymus potentially autoreactive thymocytes that are negatively selected during their maturation have been shown to present the features characteristic of apoptosis (31-36). The purpose of the present study was to determine the site(s) of clusterin gene expression and protein localization within the human thymus by the combined use of in situ hybridization and immunocytochemistry on adjacent tissue sections.

1. Abbreviation used in this paper: MAC, membrane attack complex of complement or C5b-9. 
We show here that clusterin mRNA is present in epithelial cells located within the thymic medulla while the protein is deposited within the Hassal's bodies. The putative functions of clusterin in the thymus are discussed.

\section{Methods}

Material. Four normal human thymuses were collected from children under 2 yr of age undergoing cardiac surgery, embedded in Tissue-Tek (Miles Ames Div., Miles Laboratories Inc., Elkhart, IN), frozen down in precooled methylbutane, and stored at $-70^{\circ} \mathrm{C}$ until analyzed.

Epithelial cell separation. Thymic epithelial cells and connective tissue were separated from thymocytes using a dounce homogenizer (Wheaton Industries, Millville, NJ) (37). Briefly, fresh thymus was cut into small fragments, suspended in culture medium (RPMI), and homogenized in a loose fitting glass dounce homogenizer. The cell suspension was filtered through a steel mesh, centrifuged at $800 \mathrm{~g}$ for $5 \mathrm{~min}$, washed in cold $\left(4^{\circ} \mathrm{C}\right) \mathrm{PBS}$, and centrifuged again. This procedure enables effective separation of thymic epithelium and connective tissue from thymocytes. Purity of the two populations was controlled by staining with antikeratin (Immunotech, Marseille, France), and antiCD5 (Biosys, Compiègne, France) MAbs.

Plasmid construction, in vitro transcription, and Northern blot anal$y$ sis. The clusterin sense and antisense probes, prepared from PGEM-4 ZLI, containing the full length clusterin cDNA (2), were transcribed in vitro in the presence of $12.5 \mu \mathrm{M}$ of $\alpha{ }^{32} \mathrm{P}$-labeled UTP (uridine 5'-triphosphate, $400 \mathrm{Ci} / \mathrm{mmol}$; Amersham International, Amersham, UK) or $30 \mu \mathrm{M}^{3} \mathrm{H}$-labeled UTP and $30 \mu \mathrm{M}^{3} \mathrm{H}$-labeled CTP (cytidine 5'-triphosphate, 40 and $20 \mathrm{Ci} / \mathrm{mmol}$, respectively; Amersham International). ${ }^{3} \mathrm{H}$-labeled probes were reduced to an average size of $50-100$ nucleotides by mild alkaline hydrolysis as previously described (38).

Total RNA was extracted as described elsewhere (39). RNAs were denatured with glyoxal, electrophoresed in $1.2 \%$ agarose gels, and transferred overnight onto Hybond nylon membranes (Hybond-H; Amersham International). Prehybridizations, hybridizations, and posthybridization washes were carried out as described (38).

In situ hybridizations. Minor modifications were brought to the procedure previously described (38). 5-10- $\mu \mathrm{m}$ cryostat tissue sections were mounted on poly-L-lysine (Sigma Chemical Co., St. Louis, MO) coated microscope slides, fixed in $4 \%$ glutaraldehyde in PBS for 1-5 min, rinsed in PBS, and stored in $70 \%$ ethanol at $4^{\circ} \mathrm{C}$ until analyzed. $1-3 \times 10^{6} \mathrm{cpm}$ of ${ }^{32} \mathrm{P}$-labeled cRNAs or $0.4-1 \times 10^{6} \mathrm{cpm}$ of ${ }^{3} \mathrm{H}$-labeled cRNAs were applied to each section in 20-70 $\mu$ l of hybridization mixture. After graded ethanol dehydration, sections hybridized to ${ }^{32} \mathrm{P}$-labeled cRNAs were directly exposed to $x$-ray films (SB5; Eastman Kodak Co., Rochester, NY) between intensifying screens and the films developed after 3-5 d exposure at room temperature, while sections hybridized to ${ }^{3} \mathrm{H}$-labeled cRNAs were immersed in NTB-2 emulsion (Eastman Kodak), diluted 1:1 in deionized water. After 3-15 wk exposure, they were developed in Kodak D-19 developer, fixed in $30 \% \mathrm{Na}$ thiosulfate, and counterstained in methylene blue.

Controls of specificity were performed as described $(38,40)$ and included Northern blot hybridizations as well as the use of sense RNA probes. For each experiment, control tissue sections of human testis were included, the Sertoli cells containing large amounts of clusterin mRNA. Photographs were taken with a conventional camera (Canon USA Inc., Lake Success, NY), using PANF black and white film (Ilford, Knutsford, Cheshire, England). Microphotographs were taken with a photomicroscope (Zeiss, Oberkochen, Germany), equipped with an immersion dark-field condensor, using Kodak Ektachrome 50 color film.

Immunocytochemistry. 5-10- $\mu \mathrm{m}$ serial cryostat tissue sections were prepared as described above, fixed with $1 \%$ paraformaldehyde in PBS for $5 \mathrm{~min}$, and rinsed in PBS. Slides were incubated with MAbs against CD1 (Ortho Diagnostic Systems Inc., Raritan, NJ), CD3 and CD4 (Becton Dickinson, San Jose, CA), CD5, CD68 (Dako, Glostrup, Denmark), keratin, vitronectin (Cytotech, San Diego, CA), a neoanti- gen of human $\mathrm{C} 9$ present in the MAC (MCaE11) (41) and clusterin (CLI-9) (19), washed in PBS, incubated with a rabbit antiserum to mouse Ig (Dako), washed, incubated with mouse alkaline phosphatase-antialkaline phosphatase complexes (Dako) and washed again. The color was revealed by applying the alkaline phosphatase substrate (naphthol AS-MX phosphate and Fast Red TR, Dako) along with levamisole, an inhibitor of endogenous alkaline phosphatase activity. Sections were counterstained with Hemalun of Mayer ( $0.1 \%$ for $8 \mathrm{~min}$ ) before mounting in Fluoprep (Biomérieux, Charbonnières-les-Bains, France). Microphotographs were taken with a photomicroscope (Zeiss, Oberkochen, Germany), using Kodak Ektachrome 50 color film. Controls of specificity included incubation of sections with nonimmune mouse IgG and incubation in the absence of the first $\mathrm{Ab}$.

\section{Results}

The thymus is a site of clusterin gene expression. Northern blot analysis of total RNA extracted from thymuses revealed moderate clusterin gene expression in comparison to the positive control tissue (testis), suggesting that clusterin can be synthesized by the thymus (Fig. 1). A variation of iusterin gene expression between specimens was noted, but no correlation could be made with the age of patients.

Clusterin synthesis is confined to the thymic medulla. To determine the macroscopic distribution of clusterin mRNA, we performed in situ hybridizations of thymus sections with a ${ }^{32} \mathrm{P}$-labeled cRNA probe. Hybridization with the antisense probe labeled a clearly defined zone, corresponding to the thymic medulla (Fig. 2). No signal was detectable after hybridization with the sense probe (Fig. 2).

Cells surrounding the Hassal's bodies contain most clusterin $m R N A$. To identify the cellular sites of clusterin synthesis, tissue sections were hybridized to a ${ }^{3} \mathrm{H}$-labeled probe and revealed by emulsion autoradiography. Clusterin mRNA was predominantly expressed by cells located within the thymic medulla and characterized by a large cytoplasm and a faintly stained nucleus (Fig. 3). They were scattered throughout the medulla, but predominantly around spherical structures referred to as Hassal's bodies. Furthermore, we observed a striking correlation between the intensity of the signal and the Hassal's bodies size; the smaller the Hassal's bodies, the stronger was the labeling of the cells surrounding it. No signal could be detected in cortical cells.

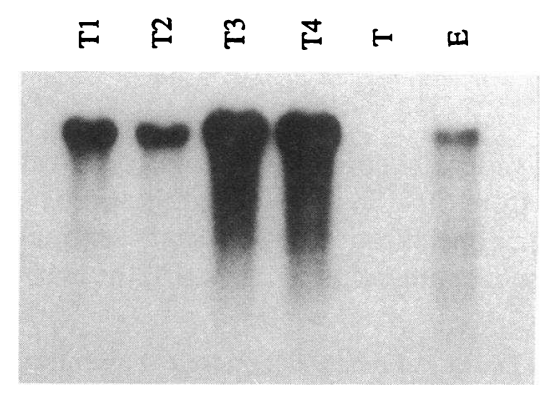

Figure 1. Northern blot analysis of clusterin mRNA of human thymus, enriched thymocyte, and epithelial cell populations. $5 \mu \mathrm{g}$ of total RNA from four human thymuses ( $T$ 1-4), enriched thymocyte $(T)$, and epithelial cell populations $(E)$ were analyzed using a clusterin cRNA probe. The membrane was exposed for $12 \mathrm{~h}$ at $-80^{\circ} \mathrm{C}$, between intensifying screens. Equal loading and the integrity of RNAs were verified by staining membranes after transfer with methylene blue. 


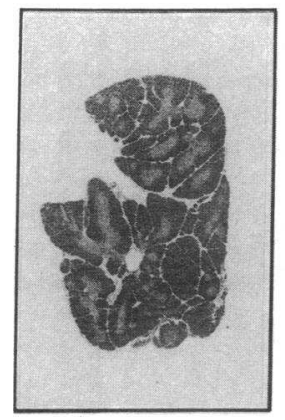

HE

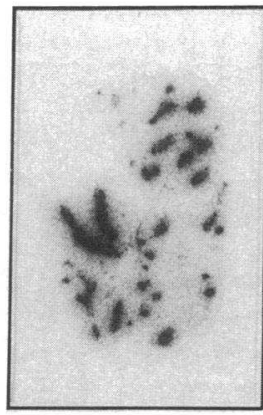

ANTISENSE

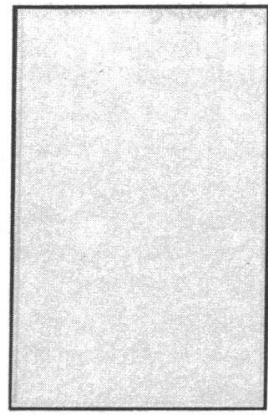

SENSE
Figure 2. Regional localization of clusterin mRNA by in situ hybridization of ${ }^{32} \mathrm{P}$-labeled cRNA probes to cryostat tissue sections of human thymus. Hematoxylin and eosin (HE) staining of a human thymus tissue section after hybridization to the antisense ${ }^{32} \mathrm{P}$-labeled cRNA probe showing the thymic cortex (dark grey) and medulla (light grey) $(\times 2)$. Autoradiogram of the section shown as hematoxylin and eosin hybridized with the antisense probe (ANTISENSE), and with the sense probe ( $S E N S E$ ) (negative control). Photographs were taken after $96 \mathrm{~h}$ (SENSE and ANTISENSE) of exposure at room temperature $(\times 2)$.

The cells containing clusterin $m R N A$ are epithelial. Immunocytochemistry of adjacent tissue sections with various MAbs enabled us to define the phenotype of the cells containing clusterin mRNA. The topography of cells labeled by the ${ }^{3} \mathrm{H}$-cRNA probe was very similar to the distribution of cells stained by the anti-keratin MAb, suggesting that they were of epithelial origin (Fig. 4). All cells containing clusterin mRNA were identified by this $\mathrm{Ab}$. However some thymocytes may contain clusterin mRNA at a low level so as to escape detection by in situ hybridization. For this reason, thymocytes were separated from the thymic epithelium and connective tissue by homogenizing the thymus in a loose fitting dounce homogenizer, and then analyzed by Northern blot. The purity of the cell populations was controlled by the staining of cell cytospins with anti-CD5 and anti-keratin MAbs. Total RNA was obtained from the thymocyte and the epithelial cell-enriched populations. As can be seen in Fig. 1, clusterin mRNA is present in the epithelial cell extract, but there is no signal in the thymocyte extract even after long exposure (not shown).

Clusterin immunoreactivity is concentrated in the Hassal's bodies' core. Staining of adjacent tissue sections with a clusterin MAb did not enable us to detect clusterin within or at the surface of cells containing clusterin mRNA. However, a strong staining with the anti-clusterin MAb was observed in the center of the Hassal's bodies (Fig. 5A). The intensity of this staining varied proportionally with the size of the bodies.

Other complement components are also present in the thymus. Clusterin being a potent inhibitor of complement-mediated cytolysis, we were interested to know whether other complement components and especially constituents of the MAC could also be detected in the thymus. Indeed, the MAC (Fig. $5 B$ ) as well as vitronectin (not shown), another inhibitor of complement mediated cytolysis, shared the same distribution pattern as clusterin in the thymus. They were both present in the center of the Hassal's bodies, and the intensity of staining by their respective MAbs also varied in proportion with Hassal's bodies' size.

\section{Discussion}

Since its identification in 1983 as a cell-aggregating glycoprotein contained in ram rete testis fluid (9), it has become clear that clusterin is a multifunctional protein with other properties, some of which are well established, such as complement inhibition $(2,4,11-13)$, but others remain still hypothetical, like its participation in the local redistribution of lipids within tissues $(7,17,19)$. Recent work by several groups has shown increased clusterin expression in epithelial or nervous tissues known to be regressing as a consequence of apoptosis (20-25), suggesting that clusterin may either be directly involved in this type of cell death or associated with the process of tissue remodeling and repair. Little is known about the expression of clusterin in the lymphoid system in which apoptosis is a frequent and prominent physiological event $(29,30)$. In the thymus, for example, apoptosis is the mechanism by which considerable numbers of potentially autoreactive thymocytes are continuously eliminated (31-36). To determine the cellular sites of clusterin synthesis in the human thymus and gain insight into its possible function(s), we have localized clusterin mRNA and protein on tissue sections of human thymus.

Our findings establish that epithelial cells surrounding Hassal's bodies are the predominant source of clusterin mRNA production, while no signal was observed in thymocytes. Different explanations might account for this unexpected finding. (a) Our techniques might have missed a small but definite expression of clusterin mRNA in thymocytes. However, the completely negative result obtained by Northern blot analysis of total RNA from purified thymocytes does not favor this possibility. ( $b$ ) Clusterin expression by thymocytes undergoing apoptosis may be so transient that at any one time too few cells contain clusterin mRNA to be detected, and $(c)$ the bulk of dying cells might be on their way to the medulla where it was not possible to exclude that apoptotic thymocytes express some clusterin. Although our studies cannot exclude these possibilities, they do not agree with the present understanding of thymocyte apoptosis which is thought to occur predominantly in the thymic cortex and to involve a large fraction of cells. Therefore it is more likely that clusterin expression by the dying cell is not essential in thymocyte apoptosis. Indeed, circulating $T$ lymphocytes do not express clusterin mRNA (7), and we could not demonstrate clusterin mRNA expression in an in vitro model of apoptosis using a pre-T lymphocyte cell line (French, L. E., A. Wohlwend, A.-P. Sappino, J. Tschopp, and J. A. Schifferli, manuscript in preparation). In addition, recent work aimed at identifying mRNAs associated with apoptotic immature thymocytes using the subtractive hybridization technique failed to demonstrate clusterin as one of the death associated mRNAs (42). Thus, several arguments support our finding that clusterin is not synthesized by thymocytes undergoing apoptosis. As a corollary, apoptosis of thymocytes does not require clusterin expression by the dying cell. This does not, however, eliminate the possibility that clusterin may be an essential component of the dying cells' environment.

Clusterin mRNA was clearly present in epithelial cells surrounding the Hassal's bodies within the thymic medulla. Whether clusterin expression by thymic epithelial cells is constitutive as in many other organs, or cell death-associated, was not determined here. Since clusterin is rapidly secreted, the negative immunostaining of epithelial cells was not unexpected, however, there was protein present in the center of the largest Hassal's bodies. Because clusterin co-localizes with the 

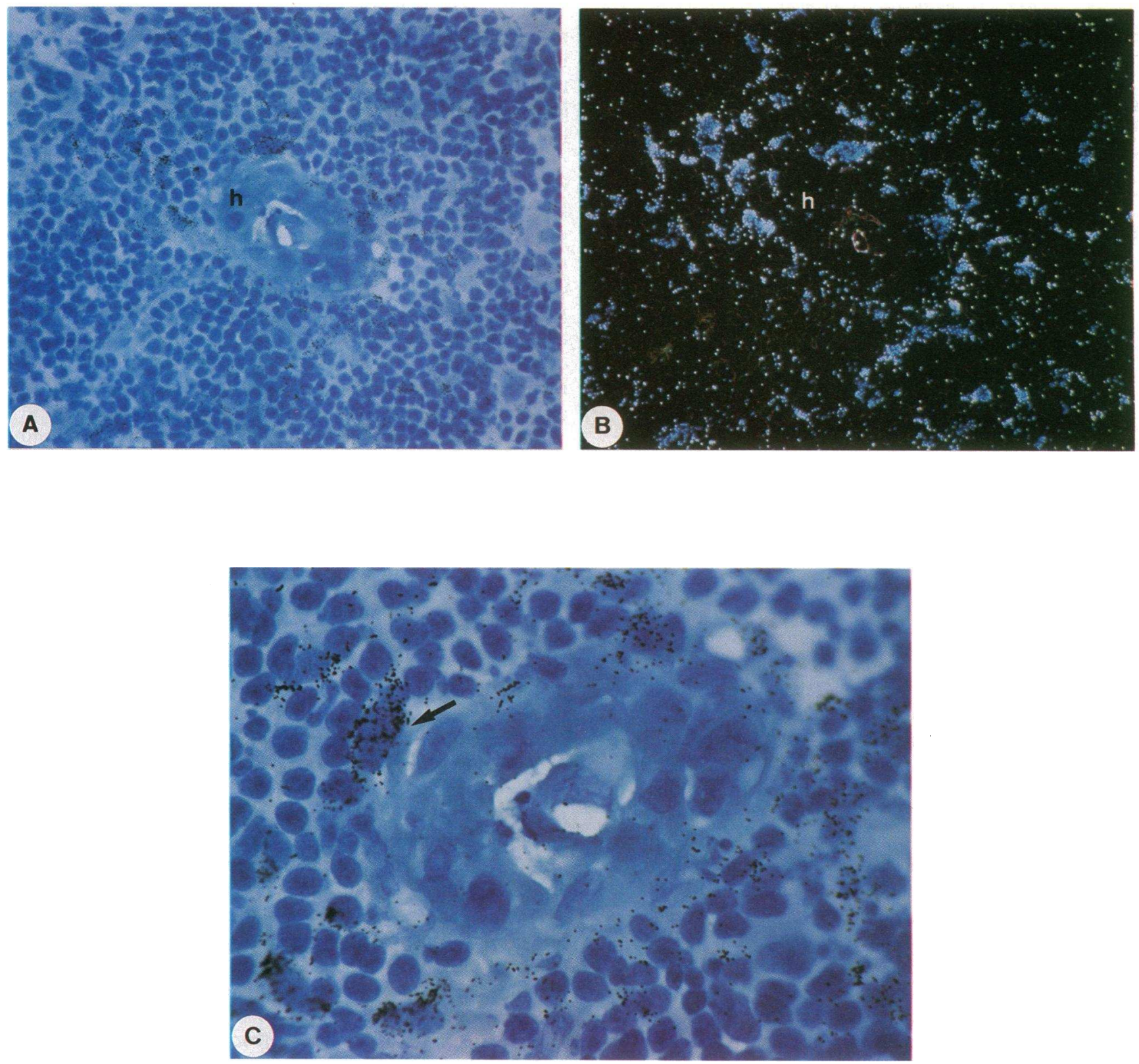

Figure 3. Cellular localization of clusterin mRNA by in situ hybridization of ${ }^{3} \mathrm{H}$-labeled cRNA probes to cryostat tissue sections of human thymus. $(A)$ is a light-field micrograph, and $(B)$ the corresponding dark-field micrograph of the thymic medulla. Cells concentrated around the Hassal's bodies $(h)$ express clusterin mRNA. $(C)$ High magnification of the Hassal body shown in $A$ : large amounts of clusterin mRNA are expressed by distinct cells characterized by a large cytoplasm (arrow). Slides were exposed for $12 \mathrm{wk}$. ( $A$ and $B, \mathrm{X} 720 ; C, \mathrm{X} 2,200$ ).

membrane attack complex of complement and vitronectin at sites of tissue injury, we speculated that complement deposits might also be present in the center of Hassal's bodies. The demonstration of MAC and vitronectin at precisely the same sites strongly suggests that clusterin was bound to MAC.

Considerable evidence exists demonstrating that the maturation pathway of thymic epithelial cells is very similar if not identical to that of the human skin (43-45). Medullary epithelial cells have been shown to differentiate through phenotypically distinct stages in vivo leading to the formation of terminally differentiated keratinized epithelial cells composing the Hassal's bodies. Furthermore, it has been postulated that thy- mic epithelial cell functional properties such as the synthesis of thymic hormones may be dependent on their stage of maturation; medullary epithelial cells being the principal source along with subcapsular thymic cortical epithelial cells $(46,47)$. Taken together with our results demonstrating clusterin synthesis by medullary epithelial cells, this would suggest that clusterin, a protein known to be associated with the process of programmed cell death in epithelial tissues, may be related to the differentiation events of thymic epithelial cells.

Thus, clusterin is synthesized in the thymus and deposited in the center of well defined epithelial structures (Hassal's bodies). Both findings suggest that clusterin has (a) definite role(s) 

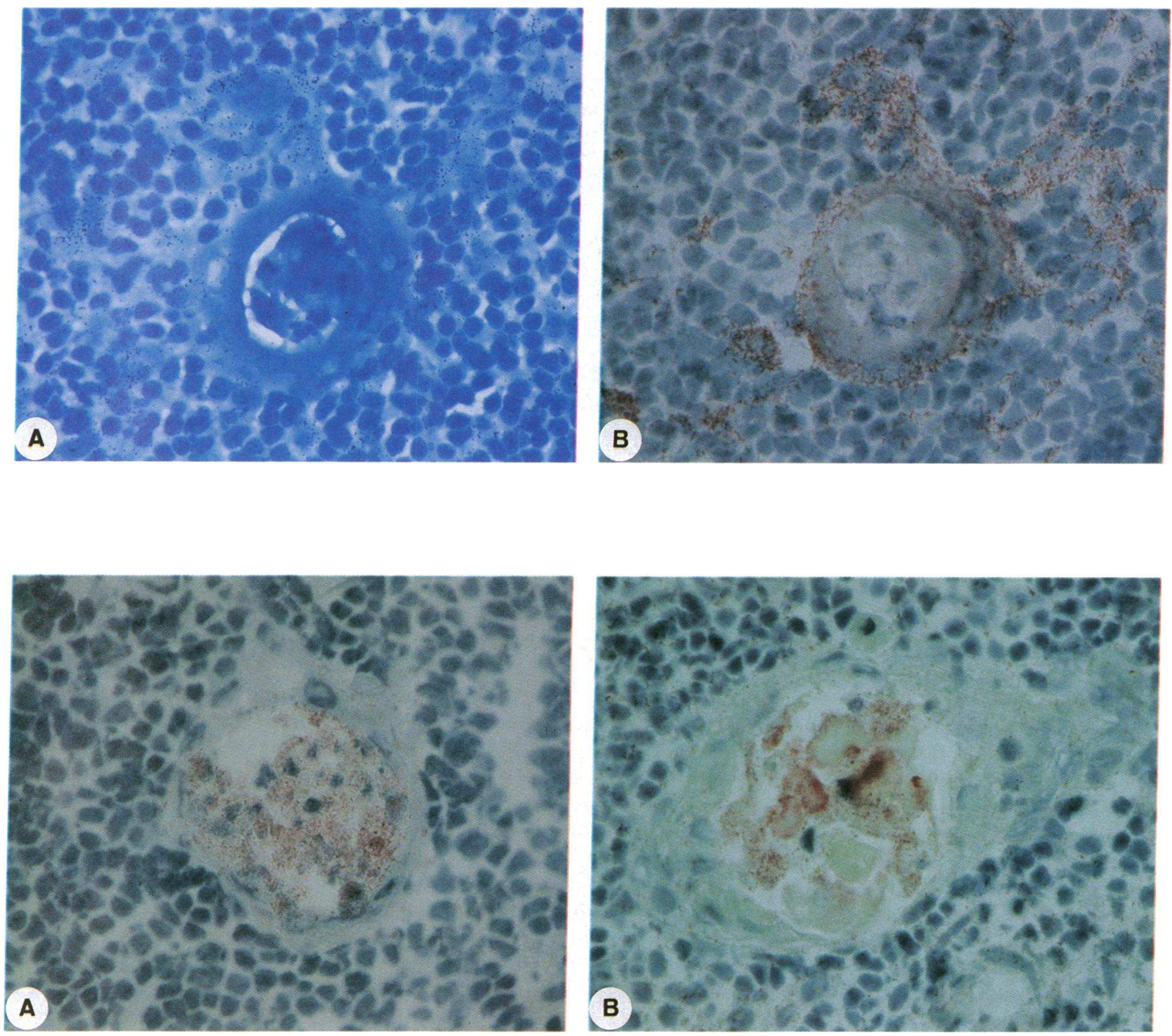

Figure 4 (top). Localization of clusterin mRNA by in situ hybridization $\left({ }^{3} \mathrm{H}\right.$-labeled cRNA probe) and cytokeratin protein by immunocytochemistry on adjacent cryostat tissue sections of human thymus. The distribution of the cells expressing clusterin mRNA $(A)$ is very similar to the distribution of cells stained by the anticytokeratin $\mathrm{MAb}(B)$. Slide $A$ was exposed for 14 wk. $(A$ and $B, \times 1,400)$.

Figure 5 (bottom). Localization of clusterin $(A)$ and the MAC $(B)$ by immunocytochemistry using specific MAbs on cryostat tissue sections of human thymus. Deposits of clusterin and MAC are visualized by the red color of the alkaline phosphatase-antialkaline phosphatase substrate in the center of the Hassal's bodies. ( $A$ and $B, \times 1,400$.)

in this organ. Indeed clusterin secreted by medullary epithelial cells may be essential for the safe disposal of cell debris generated by thymocyte apoptosis. First, clusterin forms a complex with apo A1 and may participate in the transportation of lipids between organs and from cell to cell within an organ. Several studies have demonstrated clusterin associated with the membranes of dying cells $(20,21,23,48)$. Clusterin may enable specific recognition of dying cells, and its secretion by epithelial cells may help with the removal and redistribution of membrane lipids belonging to apoptotic thymocytes. Indeed, the very similar protein apo $\mathrm{E}$ has recently been shown to be secreted by resident macrophages of the rat sciatic nerve after crush injury and participate in local cholesterol transport during regeneration and remyelination (49).

Another putative function of clusterin within the thymus could be related to its potent complement-inhibitory capacity. Cell debris are known to activate complement and MAC has been found associated with cell remnants in the kidney (5052). The co-localization of clusterin and MAC suggests that clusterin serves to minimize cytolytic MAC damage to bystander cells and thereby inflammation which is conspicuously absent in the normal thymus despite the extent of ongoing cell death.

The relative quantity of clusterin detected on thymic tissue 
sections by immunocytochemistry is greater in large Hassal's bodies, and it is known that the number of these increases with age (53). To date, Hassal's bodies have been fairly well characterized as keratinized epithelial bodies antigenically distinct from the endocrine thymic epithelium (47). Little is however known about their function(s) within the human thymus. If we accept the notion that in the thymus clusterin inhibits lytic MAC formation and helps redistribute lipids, then the presence of clusterin in the center of these large Hassal's bodies in association with the MAC and vitronectin would suggest that these are a site of disposal of cell death debris such as lipids and inactivated complement components.

In conclusion, we demonstrate here that in the human thymus clusterin is not synthesized by dying thymocytes, but by epithelial cells located essentially in the medulla around Hassal's bodies, and that it accumulates in the center of these Hassal's bodies. Although the function(s) of clusterin in the thymus remain hypothetical, these findings are the first to document the absence of clusterin expression in a cell type known to undergo apoptosis. Our results suggest that clusterin plays a role in the removal of cell debris, and may be related to the differentiation of epithelial cells.

\section{Acknowledgments}

The authors would like to thank Dr. P. Hurni for helping collect thymuses, M.-T. Morand, D. Ducrest, M. Koshbeen and G. Radlgruber for technical assistance, and J.-C. Rumbeli and J.-P. Gerber for photographic work.

This work was supported by grant number 32-32367-91 from the Fonds National Suisse pour la Recherche Scientifique. Dr. J. A. Schifferli is the recipient of a Max Cloëtta career development award.

\section{References}

1. Murphy, B. F., L. Kirszbaum, I. D. Walker, and A. J. F. d'Apice. 1988 $\mathrm{SP}-40,40$, a newly identified normal human serum protein found in the SC5b-9 complex of complement and in the immune deposits in glomerulonephritis. $J$. Clin. Invest. 81:1858-1864.

2. Jenne, D. E., and J. Tschopp. 1989. Molecular structure and functional characterization of a human complement cytolysis inhibitor found in blood and seminal plasma: identity to sulfated glycoprotein 2 , a constituent of rat testis fluid. Proc. Natl. Acad. Sci. USA. 86:7123-7127.

3. O'Bryan, M. K., H. W. G. Baker, J. R. Saunders, L. Kirszbaum, I. D. Walker, P. Hudson, D. Y. Liu, M. D. Glew, A. J. F. d'Apice, and B. F. Murphy. 1990. Human seminal clusterin $(\mathrm{SP}-40,40)$. Isolation and characterization. $J$. Clin. Invest. 85:1477-1486.

4. Kirszbaum, L., J. A. Sharpe, B. F. Murphy, A. J. d'Apice, B. Classon, P. Hudson, and I. D. Walker. 1989. Molecular cloning and characterisation of the novel, human complement-associated protein, SP-40,40: a link between the complement and reproductive systems. EMBO (Eur. Mol. Biol. Organ.) J. 8:711718.

5. Collard, M. W., and M. D. Griswold. 1987. Biosynthesis and molecular cloning of sulfated glycoprotein 2 secreted by rat sertoli cells. Biochemistry 26:3297-3303.

6. Hartmann, K., J. Rauch, J. Urban, K. Parczyk, P. Diel, C. Pilarsky, D. Appel, W. Haase, K. Mann, A. Weller, and C. Koch-Brandt. 1991. Molecular cloning of gp 80, a glycoprotein complex secreted by kidney cells in vitro and in vivo. J. Biol. Chem. 266:9924-9931.

7. De Silva, H. V., J. A. Harmony, W. D. Stuart, C. M. Gil, and J. Robbins. 1990. Apolipoprotein J: structure and tissue distribution. Biochemistry. 29:53805389.

8. Blaschuk, O., K. Burdzy, and I. B. Fritz. 1983. Purification and characterization of a cell-aggregating factor (clusterin), the major glycoprotein in ram rete testis fluid. J. Biol. Chem. 258:7714-7720.

9. Fritz, I. B., K. Burdzy, B. Setchell, and O. Blaschuk. 1983. Ram rete testis fluid contains a protein (clusterin) which influences cell-cell interactions in vitro. Biol. Reprod. 28:1173-1188.

10. Griswold, M. D., K. Roberts, and P. Bishop. 1986. Purification and charac- terization of a sulfated glycoprotein secreted by Sertoli cells. Biochemistry. 25:7265-7270.

11. Choi, N.-H., T. Mazda, and M. Tomita. 1989. A serum protein SP40,40 modulates the formation of the membrane attack complex of complement on erythrocytes. Mol. Immunol. 26:835-840.

12. Murphy, B. F., J. R. Saunders, M. K. O'Bryan, L. Kirszbaum, I. D. Walker, and A. J. F. d'Apice. 1989. SP-40,40 is an inhibitor of C5b-6 initiated hemolysis. Int. Immunol. 1:551-554.

13. Choi, N.-H., Y. Nakano, T. Tobe, T. Mazda, and M. Tomita. 1990. Incorporation of SP-40,40 into the soluble membrane attack complex (SMAC, SC5b-9) of complement. Int. Immunol. 2:413-417.

14. Murphy, B. F., D. J. Davies, W. Morrow, and A. J. F. d'Apice. 1989. Localization of terminal complement components, S-protein and SP-40,40 in renal biopsies. Pathology. 21:275-278.

15. French, L. E., L. L. Polla, J. Tschopp, and J. A. Schifferli. 1992. Membrane attack complex (MAC) deposits in skin are not always accompanied by S-protein and clusterin. J. Invest. Dermatol. 98:758-763.

16. French, L. E., J. Tschopp, and J. A. Schifferli. 1992. Clusterin in renal tissue: preferential localization with the terminal complement complex and Ig deposits in glomeruli. Clin. Exp. Immunol. 88: 389-393.

17. De Silva, H. V., W. D. Stuart, C. R. Duvic, J. R. Wetterau, M. J. Ray, D. G. Ferguson, H. W. Albers, W. R. Smith, and J. A. K. Harmony. 1990. A 70-kDa apolipoprotein designated ApoJ is a marker for subclasses of human high density lipoproteins. J. Biol. Chem. 265:13240-13247.

18. James, R. W., A. C. Hochstrasser, I. Borghini, B. Martin, D. Pometta, and D. Hochstrasser. 1991. Characterization of a human high density lipoprotein-associated protein, NA1 / NA2. Identity with SP-40,40, an inhibitor of complement-mediated cytolysis. Arteriosclerosis Thromb. 11:645-652.

19. Jenne, D. E., B. Lowin, M. C. Peitsch, A. Böttcher, G. Schmitz, and J. Tschopp. 1991. Clusterin (complement lysis inhibitor) forms a high density lipoprotein complex with apolipoprotein A-1 in human plasma. J. Biol. Chem. 266:11030-11036.

20. Buttyan, R., C. A. Olsson, J. Pintar, C. Chang, M. Bandyk, P.-Y. Ng, and I. S. Sawczuk. 1989. Induction of the TRPM-2 gene in cells undergoing programmed death. Mol. Cell. Biol. 9:3473-3481.

21. Bandyk, M. G., I. S. Sawczuk, C. A. Olsson, A. E. Katz, and R. Buttyan. 1990. Characterization of the products of a gene expressed during androgen-programmed cell death and their potential use as a marker of urogenital injury. $J$. Urol. 143:407-413.

22. Grima, J., I. Zwain, R. A. Lockshin, C. W. Bardin, and C. Y. Cheng. 1990. Diverse secretory patterns of clusterin by epididymis and prostate/seminal vesicles undergoing cell regression after orchiectomy. Endocrinology. 126:29892997.

23. Sensibar, J. A., M. D. Griswold, S. R. Sylvester, R. Buttyan, C. W. Bardin, C. Y. Cheng, S. Dudek, and C. Lee. 1991. Prostatic ductal system in rats: regional variation in localization of an androgen-repressed gene product, sulfated glycoprotein-2. Endocrinology. 128:2091-2102.

24. Connor, J., R. Buttyan, C. A. Olsson, V. D'Agati, K. O'Toole, and I. S. Sawczuk. 1991. SGP-2 expression as a genetic marker of progressive cellular pathology in experimental hydronephrosis. Kidney Int. 39:1098-1103.

25. May, P. C., M. Lampert-Etchells, S. A. Johnson, J. Poirier, J. N. Masters, and C. E. Finch. 1990. Dynamics of gene expression for a hippocampal glycoprotein elevated in Alzheimer's disease and in response to experimental lesions in rat. Neuron. 5:831-839.

26. Wyllie, A. H., J. F. R. Kerr, and A. R. Currie. 1980. Cell death: the significance of apoptosis. Int. Rev. Cytol. 68:251-306.

27. Duvall, E., and A. H. Wyllie. 1986. Death and the cell. Immunol. Today. 7:115-119.

28. Wyllie, A. H., R. G. Morris, A. L. Smith, and D. Dunlop. 1984. Chromatin cleavage in apoptosis: association with condensed chromatin morphology and dependence on macromolecular synthesis. J. Pathol. 142:67-77.

29. Golstein, P., D. M. Ojcius, and D.-E. Young. 1991. Cell death mechanisms and the immune system. Immunol. Rev. 121:29-65.

30. Cohen, J. J. 1991. Programmed cell death in the immune system. $A d v$. Immunol. 50:55-85.

31. Kappler, J. W., N. Roehm, and P. Marrack. 1987. T cell tolerance by clonal elimination in the thymus. Cell. 49:273-280.

32. Von Boehmer, H. 1988. The developmental biology of T lymphocytes. Annu. Rev. Immunol. 6:309-326.

33. MacDonald, H. R., R. C. Howe, T. Pedrazzini, R. K. Lees, R. C. Budd, R. Schneider, N. S. Liao, R. M. Zinkernagel, J. A. Louis, D. H. Raulet, et al. 1988 T-cell lineages, repertoire selection and tolerance induction. Immunol. Rev. 104:157-182.

34. Von Boehmer, H., H. S. Teh, and P. Kisielow. 1989. The thymus selects the useful, neglects the useless and destroys the harmful. Immunol. Today. 10:5761.

35. Dent, A. L., L. A. Matis, F. Hooshmand, S. M. Widacki, J. A. Bluestone, and S. M. Hedrick. 1990. Self-reactive gamma delta T cells are eliminated in the thymus. Nature (Lond.). 343:714-719. 
36. MacDonald, H. R., and R. K. Lees. 1990. Programmed death of autoreactive thymocytes. Nature (Lond.). 343:642-644.

37. Compton, M. M., and J. A. Cidlowski. 1987. Identification of a glucocorticoid-induced nuclease in thymocytes. A potential "lysis gene" product. J. Biol. Chem. 262:8288-8292.

38. Sappino, A.-P., J. Huarte, J.-D. Vassalli, and D. Belin. 1991. Sites of synthesis of urokinase and tissue-type plasminogen activators in the murine kidney. J. Clin. Invest. 87:962-970.

39. Sappino, A.-P., N. Busso, D. Belin, and J.-D. Vassalli. 1987. Increase of urokinase-type plasminogen activator gene expression in human lung and breast carcinomas. Cancer Res. 47:4073-4046.

40. Huarte, J., D. Belin, D. Bosco, A.-P. Sappino, and J.-D. Vassalli. 1987. Plasminogen activator and mouse spermatozoa: urokinase synthesis in the male genital tract and binding of the enzyme to the sperm cell surface. J. Cell Biol. 104:1281-1289.

41. Mollnes, T. E., T. Lea, M. Harboe, and J. Tschopp. 1985. Monoclonal antibodies recognizing a neoantigen of poly $(\mathrm{C} 9)$ detect the human terminal complement complex in tissue and plasma. Scand. J. Immunol. 22:183-195.

42. Owens, G. P., W. E. Hahn, and J. J. Cohen. 1991. Identification of mRNAs associated with programmed cell death in immature thymocytes. $\mathrm{Mol}$. Cell. Biol. 11:4177-4188.

43. Laster, A. J., T. Itoh, T. J. Palker, and B. F. Haynes. 1986. The human thymic microenvironment: thymic epithelium contains specific keratins associated with early and late stages of epidermal keratinocyte maturation. Differentiation. 31:67-77.

44. Lobach, D. F., T. Itoh, K. H. Singer, and B. F. Haynes. 1987. The thymic microenvironment. Characterization of in vitro differentiation of the IT26R21 rat thymic epithelial cell line. Differentiation. 34:50-59.
45. Lobach, D. F., and B. F. Haynes. 1987. Ontogeny of the human thymus during fetal development. J. Clin. Imṁunol. 7:81-97.

46. Haynes, B. F. 1984. Phenotypic characterization and ontogeny of the human thymic microenvironment. Clin. Res. 32:500-507.

47. Lobach, D. F., R. M. Scearce, and B. F. Haynes. 1985. The human thymic microenvironment. Phenotypic characterization of Hassal's bodies with the use of monoclonal antibodies. J. Immunol. 134:250-257.

48. Sawczuk, I. S., G. Hoke, C. A. Olsson, J. Connor, and R. Buttyan. 1989. Gene expression in response to acute unilateral ureteral obstruction. Kidney Int. 35:1315-1319.

49. Boyles, J. K., C. D. Zoellner, L. J. Anderson, L. M. Kosik, R. E. Pitas, K. H. Weisgraber, D. Y. Hui, R. W. Mahley, P. J. Gebicke-Haerter, M. J. Ignatius, and E. M. Shooter. 1989. A role for apolipoprotein E, apolipoprotein A-1, and low density lipoprotein receptors in cholesterol transport during regeneration and remyelination of the rat sciatic nerve. J. Clin. Invest. 83:1015-1031.

50. Hinglais, N., M. D. Kazatchkine, S. Bhakdi, M.-D. Appay, C. Mandet, J. Grosstete, and J. Bariety. 1986. Immunohistochemical study of the C5b-9 complex of complement in human kidneys. Kidney Int. 30:399-410.

51. Falk, R. J., A. P. Dalmasso, Y. Kim, C. H. Tsai, J. I. Scheinman, H. Gewurz, and A. F. Michael. 1983. Neoantigen of the polymerized ninth component of complement. Characterization of a monoclonal antibody and immunohistochemical localization in renal disease. J. Clin. Invest. 72:560-573.

52. Falk, R. J., S. P. Sisson, A. P. Dalmasso, Y. Kim, A. F. Michael, and R. L. Vernier. 1987. Ultrastructural localization of the membrane attack complex of complement in human renal tissues. Am. J. Kidney Dis. 9:121-128.

53. Steinmann, G. C., B. Klaus, and H.-K. Müller-Hermelink 1985. The involution of the ageing human thymic epithelium is independent of puberty. A morphometric study. Scand. J. Immunol. 22:563-575. 